\title{
Editorial
}

\section{Expert Commentary on Rare (Nonvestibular, Nontrigenimal) Cranial Nerve Schwannomas}

Cranial nerve schwannomas are benign nerve sheath tumors that may arise along the course of cranial nerves throughout the cranium or neck. They may occur spontaneously or in the context of familial tumor syndromes such as neurofibromatosis type 2 (NF2), schwannomatosis, and Carney's complex. ${ }^{[1]}$ Schwannomas behave as the World Health Organization grade I tumors and only very rarely undergo malignant transformation. The pathogenesis of these tumors is based on loss of function of Merlin which is a multifunctional protein including tumor-suppressing activity. The main mechanisms on the development of functional loss in merlin are genetic change involving the NF2 gene on chromosome 22 and/or direct merlin inactivation by phosphorylation. ${ }^{[2]}$

The tumor is characteristically arises from the sheath of a nerve fascicle as a focal solid lesion forming a well-demarcated, eccentric mass deflecting the parent nerve in time. The schwannomas are encapsulated with a smooth, sometimes lobulated, external surface. In general, secondary degenerative alterations are present in large lesions including yellow fatty areas and cysts of varying sizes. In some instances, red or maroon discoloration could be observed, signifying recent or remote hemorrhage. Schwannomas are classically composed of two distinct alternating architectural patterns, designated Antoni A and Antoni B areas. Antoni A areas comprise compact strands and fascicles of spindle cells that are delicately fibrillated. On the other hand, Antoni B areas consist of more loosely arranged vacuolated cells that tend to be pleomorphic.

Patients with cranial nerve schwannomas could either present with loss of function of the affected nerve or incidentally discovered on computed tomography (CT) or magnetic resonance imaging (MRI) obtained for the reasons other than the evaluation of a neoplasm. Although they can arise from all cranial nerves with the exception of the optic nerve, vestibular schwannomas are the most common cranial nerve schwannomas followed by trigeminal ones. Intracranial schwannomas arising from the origins other than vestibular or trigeminal nerves are very rare and constituting $<0.8 \%$ of all schwannomas. In the paper of Dr. Harsh Deora et al., ${ }^{[3]}$ they report on 16 such cases including seven facial nerve, four olfactory groove, three sixth-nerve and two third-nerve schwannomas. Eleven patients had undergone microsurgical resection and five had been sent to stereotactic radiosurgery. Although the olfactory nerve lacks Schwann cells, schwannomas may occur in olfactory groove also either by originating from the perivascular nerve plexus, meningeal branches of the trigeminal nerve, or anterior ethmoidal nerve or from ectodermal Schwann cells developed by transformation of mesenchymal pial cell or migration of the neural crest cells within the substance of the central nervous system. Dr. et al. ${ }^{[3]}$ also share their experiences on four cases with olfactory groove schwannomas in their paper. The schwannomas present with either loss of function of originated cranial nerve or symptoms due to their mass effect. In accordance, the patients in the case series of Dr. et al..$^{[3]}$ also have a wide spectrum of signs due to compression of adjacent brain structures or neighbor cranial nerves beside the varying signs owing to originated cranial nerve. For example, most of their patients with facial nerve schwannomas presenting with sudden facial weakness have also hearing loss or dizziness and unsteadiness of gait with cerebellar signs.

The schwannomas arising from an unexpected origin compose major diagnostic challenges in terms of causing confusion with its nerve of origin and the kind of neoplasms. ${ }^{[4]}$ Schwannomas should also be considered in the differential diagnoses of unusual masses in the cranium or neck. Preoperative detailed neuroimaging elicits valuable information regarding the location and origin of schwannomas, and histopathology of resected material confirms the diagnosis. CT and/or MRI reveal valuable information regarding the location and origin of the tumor as well as aiding surgical planning. MRI including $\mathrm{T} 2 \mathrm{~W}$ or $\mathrm{T} 2 * \mathrm{~W}$ sequences is the imaging modality of choice, and CT is supplementary to MRI, particularly for tumors located in the skull base. ${ }^{[5,6]}$ The diagnosis can only be confirmed intraoperatively in many cases with unusual locations.

Although the ideal treatment for symptomatic patients with schwannoma is the total excision of the tumor, the other options for management are observation, subtotal removal, and various forms of radiation treatment, including stereotactic radiosurgery. Selection of the appropriate management should be individualized considering the age, general health status and the clinical findings of the patients, and the location, size, and relationships of the tumor with adjacent structures.

Murat Alemdar

Department of Neurology, Sakarya University Education and Research Hospital, Neurology Clinic, Sakarya, Turkey 
Address for correspondence: Assoc. Prof. Dr. Murat Alemdar, Sakarya University Education and Research Hospital, Neurology Clinic, 2. Kat, Adnan Menderes c., Sağlik s., No: 195, 54100, Adapazari, Sakarya, Turkey. E-mail:dr.alemdar@gmail.com

\section{REFERENCES}

1. Hilton DA, Hanemann CO. Schwannomas and their pathogenesis. Brain Pathol 2014;24:205-20.

2. Ruttledge MH, Rouleau GA. Neurofibromatosis Type 2: Further questions and answers. In: Squire LR, editor. Encyclopedia of Neuroscience. Oxford: Academic Press; 2009. p. 427-32.

3. Deora H, Srinivas D, Beniwal M, Vikas V, Rao KVLN, Somanna S. Rare Cranial Nerve Schwannomas: A Retrospective Review of Nontrigeminal, Nonvestibular Cranial Nerve Schwannomas. J Neurosci Rural Pract 2018;9:258-63.

4. Behuria S, Rout TK, Pattanayak S. Diagnosis and management of schwannomas originating from the cervical vagus nerve. Ann R Coll Surg Engl 2015;97:92-7.

5. Fortnum H, O’Neill C, Taylor R, Lenthall R, Nikolopoulos T, Lightfoot $\mathrm{G}$, et al. The role of magnetic resonance imaging in the identification of suspected acoustic neuroma: A systematic review of clinical and cost effectiveness and natural history. Health Technol Assess 2009; 13:iii-iv, ix-xi, 1-154.

6. Agarwal A. Intracranial trigeminal schwannoma. Neuroradiol J 2015;28:36-41.

This is an open access journal, and articles are distributed under the terms of the Creative Commons Attribution-NonCommercial-ShareAlike 4.0 License, which allows others to remix, tweak, and build upon the work non-commercially, as long as appropriate credit is given and the new creations are licensed under the identical terms.

\begin{tabular}{|l|l|}
\hline \multicolumn{2}{|c|}{ Access this article online } \\
\hline Quick Response Code: & Website: \\
\hline & www.ruralneuropractice.com \\
& \\
& \\
\hline
\end{tabular}

How to cite this article: Alemdar M. Expert commentary on rare (nonvestibular, nontrigenimal) cranial nerve schwannomas. J Neurosci Rural Pract 2018;9:175-6. 